\title{
Airway versus transbronchial biopsy and BAL in lung transplant recipients: different but complementary
}

\author{
C. Ward, G.I. Snell, B. Orsida, L. Zheng, T.J. Williams, E.H. Walters
}

\begin{abstract}
Airway versus transbronchial biopsy and BAL in lung transplant recipients: different but complementary. C. Ward, G.I. Snell, B. Orsida, L. Zheng, T.J. Williams, E.H. Walters. CERS Journals Ltd 1997.

ABSTRACT: Lung transplantation is now an established therapeutic intervention for end-stage cardiopulmonary disease in humans. Chronic rejection, in the form of bronchiolitis obliterans syndrome (BOS), remains the commonest cause of morbidity and mortality in those surviving more than 3 months. The pathology of BOS involves airway changes. We have evaluated the potential for endobronchial biopsies (EBB) to complement existing sampling methods used in allograft monitoring and have compared the results of EBB findings with those of bronchoalveolar lavage (BAL) and transbronchial biopsy (TBB) in 18 clinically stable patients.

We found that all the EBB had inflammatory cells present but that only five TBB specimens had evidence of inflammation, with airway material being present in $78 \%$ of the TBB. Paired BAL and EBB yielded different results, with no correlations between total macrophages, lymphocytes, CD4+ cells or CD8+ cells.

We conclude that endobronchial biopsies are potentially useful as an additional sample for the monitoring of inflammation in lung allografts, since they yield different, and potentially complimentary, information to bronchoalveolar lavage and transbronchial biopsy.
\end{abstract}

Eur Respir J 1997; 10: 2876-2880
Dept of Respiratory Medicine, Alfred Hospital and Monash University Medical School, Melbourne, Australia.

Correspondence: E.H Walters

Dept of Respiratory Medicine

Alfred Hospital

Prahran

Melbourne

Victoria 3181

Australia

Keywords: Bronchoalveolar lavage endobronchial biopsy

lung transplant

transbronchial biopsy

Received: April 21997

Accepted after revision July 311997

Supported by a grant from the Alfred Hospital Foundation
Chronic rejection, in the form of bronchiolitis obliterans syndrome (BOS) [1,2], remains the commonest cause of morbidity and mortality in those surviving lung transplantation for more than 3 months. The reported prevalence in lung transplant populations is estimated to be $10-54 \%[3,4]$, with a mortality rate of $50 \%$ [5]. In spite of this high prevalence, BOS has received little study in humans and its immunopathology remains poorly understood.

Although open lung biopsy is regarded as the "gold standard" method for diagnosing chronic rejection [6], this procedure is generally regarded as unacceptably invasive and is essentially unrepeatable [7]. Less invasive means of sampling lung tissue include bronchoalveolar lavage (BAL) and transbronchial biopsy (TBB) [8].

BAL, with poor reported sensitivity and specificity, has generally been regarded as of little value in the detection of chronic rejection, and instead has been mainly used in the detection of infection [8].

TBB, initially advocated by the Papworth Hospital group in Cambridge, UK, is at present regarded as the most specific and practical way of defining acute and chronic lung rejection. The currently accepted pathological grading scheme is based on this sampling method [8]. However, TBB has some disadvantages [9]. For adequate sensitivity, large numbers of TBB specimens need to be taken, with one study advocating 18 samples [10]. Currently, it is recommended that a minimum of five TBBs, are taken [7]; however, a significantly decreased sensitivity has been reported where fewer than nine specimens have been taken [11]. The need for ade- quate numbers of specimens must be balanced against morbidity in a clinical risk/benefit estimation. It has been shown that TBB can lead to complications in around $10 \%$ of patients [12], including bleeding, pneumothorax [8] and even death [13].

Furthermore, attention has tended to focus on the assessment of acute "lung" rejection using TBB of lung parenchyma to categorize perivascular phenomena. The hallmarks of chronic rejection in the form of BOS are likely to involve airway changes [7]. The yield of useful bronchiolar tissue from such specimens is variable but frequently poor. Estimates for the sensitivity of diagnosing BOS from TBB specimens have ranged from $15 \%$ [5] to $87 \%$ [14].

Hence, all of the sampling strategies tested so far in the monitoring of lung allografts have potential drawbacks, particularly with reference to their utility in assessing BOS. Limited data are emerging on EBB findings in stable lung transplant recipients [15-17] and BOS $[15,16]$ but with some conflict in the preliminary findings, possibly relating to differences in patient selection, therapeutic management and methodological issues $[16,17]$. At the moment, therefore, there are few published data available on EBB findings in lung transplantation and no comparison with TBB and BAL.

In this study, we have compared TBB carried out and analysed histologically according to current guidelines, which represent the presently accepted routine standard for the investigation of lung allograft rejection [2], against the results of detailed immunohistological analyses of EBB and BAL in 18 clinically stable lung transplant recipients. 


\section{Methods}

BAL, EBB and TBB were taken from 18 clinically stable single lung, double lung or heart-lung recipients at routine follow-up, 2-36 months post-transplantation. Clinical details are presented in table 1. Patients were excluded if they had intercurrent lung infection, or either acute or chronic lung rejection. The study was approved by the Alfred Hospital Ethics Review Committee.

\section{Immunosuppression and surveillance}

Immunosuppressive protocols were similar to those reported by other centres [9]. All patients began triple therapy immediately after the operation. Maintenance therapy included cyclosporin (to achieve a blood level of 200-350 $\mu \mathrm{g} \cdot \mathrm{L}^{-1}$ (EMIT assay, parent drug only; Syva, California, USA)), azathioprine (1.0-2.0 $\mathrm{mg} \cdot \mathrm{kg}^{-1}$ daily), and prednisolone $\left(0.15-0.25 \mathrm{mg} \cdot \mathrm{kg}^{-1}\right.$ daily $)$.

\section{Fibreoptic bronchoscopy with BAL and biopsies}

Bronchoscopies were carried out as described previously [17]. Briefly, upper and lower airways were anaesthetized with topical $1.5 \%$ lidocaine, and a $3 \times 60 \mathrm{~mL}$ $\mathrm{BAL}$ of the middle lobe or lingula segment was carried out after wedging the bronchoscope in a suitable subsegment. The fluid was immediately aspirated into a glass container at a negative pressure of approximately -10.6 $\mathrm{kPa}(-80 \mathrm{mmHg})$ and transported to the laboratory at $4^{\circ} \mathrm{C}$. BAL was followed by EBB then TBB. EBB samples were taken from subsegmental carini of the lower lobes. Alligator forceps were used throughout for biopsy samples (Olympus, FB 15C; Japan). All recipients had venepuncture for cyclosporin assay and also lung function tests performed immediately prior to the procedure. The forced expiratory volume in one second (FEV1) was compared to the recipients previous best value post-transplantation to ascertain the percentage of maximal FEV1.

\section{$B A L$ cell processing}

Total cell counts were performed on the unfiltered BAL fluid using a modified Neubauer haemocytometer. Duplicate cytocentrifuge preparations were made using $200 \mu \mathrm{L}$ of unfiltered BAL aspirate (Shandon Cytospin III; $82 \times \mathrm{g}$ for $10 \mathrm{~min}$ ), and cell counts were performed by counting 500 cells on each slide, and obtaining a mean result. BAL fluid was then filtered through a $200 \mu \mathrm{m}$ nylon mesh, and the cells pelleted at $100 \times \mathrm{g}$ for $15 \mathrm{~min}$ for subsequent flow cytometry.

\section{Flow cytometry}

BAL cell pellets were resuspended to a cell concentration of $2 \times 10^{6}$ cells $\cdot \mathrm{mL}^{-1}$ in phosphate-buffered saline (PBS), and $50 \mu \mathrm{L}$ aliquots were then incubated with 30 $\mu \mathrm{L}$ of monoclonal antibodies, directly conjugated to either phycoerythrin (PE; red fluorochrome), fluorescein isothiocyanate (FITC; green fluorochrome), or PERCP (orange fluorochrome) as a third colour. The antibody combinations used were CD45/CD14 (leucogate; allowing the identification of lymphocytes), CD4/CD8/CD3 (helper/inducer, suppressor/cytotoxic and total T-cells), CD4/CD25/CD3 (CD25 expression on T-cells is an alternative index of activation) and an isotype control (all Becton Dickinson antibodies; San Jose, California, USA). Following staining for $20 \mathrm{~min}$ at $4^{\circ} \mathrm{C}$, cells were washed in $2 \mathrm{~mL}$ of PBS, centrifuged ( $15 \mathrm{~min}$ at $100 \times \mathrm{g})$, and analysed using a flow cytometer (FACScan; Becton Dickinson). Lymphocytes were gated using the leucogate tube on forward and side light scatter, verified using the characteristic staining pattern of lymphocytes with CD45

Table 1. - Clinical details of the stable lung transplant recipients studied

\begin{tabular}{|c|c|c|c|c|c|c|c|c|c|c|}
\hline $\begin{array}{l}\mathrm{Pt} \\
\text { No. }\end{array}$ & Sex & $\begin{array}{l}\text { Age } \\
\text { yrs }\end{array}$ & $\begin{array}{l}\text { Original } \\
\text { disease }\end{array}$ & $\begin{array}{c}\text { Days } \\
\text { post-Tx }\end{array}$ & $\begin{array}{c}\mathrm{FEV} 1 \\
\% \text { max } \\
\text { post-Tx }\end{array}$ & $\begin{array}{l}\text { Rejection } \\
\text { grade\$ }^{\$}\end{array}$ & $\begin{array}{c}\text { BAL } \\
\text { microbes }\end{array}$ & $\begin{array}{c}\text { CsA } \\
\text { level }^{\#} \\
\mathrm{mg} \cdot \mathrm{L}^{-1}\end{array}$ & $\begin{array}{c}\text { Pred } \\
\text { dose* } \\
\mathrm{mg}\end{array}$ & $\begin{array}{c}\text { Aza } \\
\text { dose* } \\
\text { mg }\end{array}$ \\
\hline 1 & M & 34 & $\mathrm{Br}$ & 376 & 84 & $\mathrm{~A} 1 \mathrm{~B} 0$ & Nil & 162 & 15 & 25 \\
\hline 2 & $\mathrm{~F}$ & 32 & $\mathrm{CF}$ & 67 & 95 & $\mathrm{~A} 0 \mathrm{~B} 0$ & Nil & 360 & 15 & 75 \\
\hline 3 & $\mathrm{~F}$ & 23 & $\mathrm{CF}$ & 102 & 100 & $\mathrm{~A} 0 \mathrm{~B} 0$ & Nil & 257 & 15 & 25 \\
\hline 4 & $\mathrm{~F}$ & 41 & $\mathrm{PPH}$ & 200 & 100 & A1B2 & $\mathrm{CMV}, \mathrm{Sa}$ & 195 & 15 & 125 \\
\hline 5 & M & 36 & $\mathrm{CF}$ & 75 & 100 & A1B2 & Psa, ASP & 820 & 20 & 75 \\
\hline 6 & $\mathrm{~F}$ & 34 & $\mathrm{Ei}$ & 190 & 100 & $\mathrm{~A} 0 \mathrm{~B} 0$ & CMV & 264 & 15 & 75 \\
\hline 7 & $\mathrm{~F}$ & 35 & $\mathrm{Ei}$ & 419 & 100 & $\mathrm{~A} 0 \mathrm{~B} 0$ & Nil & 210 & 12.5 & 75 \\
\hline 8 & $\mathrm{~F}$ & 42 & $\mathrm{Ei}$ & 542 & 100 & A1BX & Nil & 134 & 7.5 & 50 \\
\hline 9 & M & 22 & $\mathrm{CF}$ & 186 & 100 & $\mathrm{~A} 1 \mathrm{BX}$ & CMV & 432 & 7.5 & 50 \\
\hline 10 & $\mathrm{~F}$ & 31 & $\mathrm{CF}$ & 58 & 100 & A1B2 & CMV & 710 & 20 & 50 \\
\hline 11 & $\mathrm{M}$ & 33 & $\mathrm{Ei}$ & 1301 & 100 & $\mathrm{~A} 0 \mathrm{~B} 0$ & Spn & 265 & 7.5 & 100 \\
\hline 12 & M & 46 & $\mathrm{Sa}$ & 146 & 100 & $\mathrm{~A} 0 \mathrm{~B} 2$ & CMV & 311 & 17.5 & 25 \\
\hline 13 & $\mathrm{~F}$ & 46 & $\mathrm{Br}$ & 107 & 100 & A1BX & $S a$ & 307 & 15 & 50 \\
\hline 14 & $\mathrm{~F}$ & 40 & $\mathrm{Br}$ & 189 & 100 & $\mathrm{~A} 1 \mathrm{~B} 0$ & Nil & 225 & 12.5 & 50 \\
\hline 15 & M & 20 & $\mathrm{Ei}$ & 732 & 99 & $\mathrm{~A} 0 \mathrm{~B} 0$ & Nil & 243 & 7.5 & 100 \\
\hline 16 & M & 39 & $\mathrm{CF}$ & 547 & 91 & A1B0 & Psa, CMV & 493 & 7.5 & 50 \\
\hline 17 & $\mathrm{~F}$ & 50 & $\mathrm{Em}$ & 376 & 92 & $\mathrm{~A} 1 \mathrm{BX}$ & CMV & 402 & 15 & 75 \\
\hline 18 & M & 55 & $\mathrm{Em}$ & 545 & 99 & A1B3 & Psa, CMV & 301 & 7.5 & 100 \\
\hline
\end{tabular}

$\$$ : $A=$ acute rejection $0-4, \mathrm{~B}=$ bronchiolar inflammation $0-4$ (X=ungradable) on transbronchial biopsy (TBB); \#: blood level; *: oral dose. Pt: patient; M: male; F: female; post-Tx: post-transplant; BAL: bronchoalveolar lavage; FEV1: forced expiratory volume in one second; Br: bronchiectasis; CF: cystic fibrosis; Em: emphysema; Sa: sarcoid; Ei: Eisenmenger's syndrome; PPH: primary pulmonary hypertension; ASP: aspergillus; Spn: Staphylococcus pneumoniae; Sa: Staphylococcus aereus; Psa: Pseudomonas aeruginosa (culture); CMV: cytomegalovirus (viral immunofluorescence assay (IFA)); CsA: cyclosporin A; Pred: prednisolone; Aza: azathioprine. 
(common leucocyte antigen), and lack of staining with CD14 (a monocyte/macrophage marker). Lysis II software was used for analysis (Becton Dickinson).

\section{Endobronchial biopsies}

Four specimens were taken from lower lobe subcarinae using alligator forceps (Olympus, FB 15C; Japan) and placed into chilled saline. Biopsies, embedded in ornithine carbanyl transferase (OCT (a glycerol-based freezing matrix); Sigma, St Louis, Missouri, USA), were snap frozen in a liquid $\mathrm{N}_{2}$-chilled isopentane slurry, and then sectioned on a high performance cryostat, immediately or after storage at $-70^{\circ} \mathrm{C}$.

Frozen tissue sections of $7 \mu \mathrm{m}$ were fixed in a paraformaldehyde-based fixative (PLP) for $15 \mathrm{~min}$ at $4^{\circ} \mathrm{C}$ prior to staining. The staining panel (DAKO, Denmark) for lymphocyte typing included anti-CD3,-CD4 and-CD8. Anti-CD25 was used as a T-cell activation marker. AntiCD68 was used as a marker of macrophages. Staining for cell subsets and activation markers was undertaken using a standard three layer immunoperoxidase stain (Vectastain Elite ABC kit; Vector Laboratories, California, USA) using diaminobenzidine (DAB) substrate (DAKO, Denmark). Irrelevant antibodies, including immunoglobulin G1 (IgG1) and immunoglobulin G2a (IgG2a) (DAKO, Denmark), were used as negative controls. Human tonsil and nasal polyp were used as positive controls, as appropriate.

Quantification of cells and antigen in EBB. For quantification a computerized colour image analysis system (Video Pro 32; Leading Edge, Sydney, Australia) was utilized. Two sections, $30 \mu \mathrm{m}$ apart, were examined by a single experienced observer, blinded to the results of the BAL and TBB investigations. The submucosa was analysed to a depth of $150 \mu \mathrm{m}$ below the basement membrane in five nonoverlapping high power fields. Only nucleated, stained cells, were counted as positive, and cells within vascular spaces were excluded. Counts were expressed per millimetre of basement membrane.

\section{Transbronchial lung biopsies}

Five to seven TBBs were taken using alligator forceps (Olympus, FB 15C; Japan) for haematoxylin and eosin staining to assess acute or chronic rejection according to standard criteria by the Alfred Hospital Department of Anatomical Pathology. The assessment, performed by a trained specialist pathologist, was made blind with respect to the other investigations and yielded a standard grade of inflammation [2].

\section{Statistical analysis}

Because of the variation in BAL total cell counts in the subjects studied, it was prospectively decided to analyse the BAL data as absolute cell counts. Correlation coefficients ( $r$ ) for a limited number of prospectively defined end-points were obtained using a rank-based method, in order to prevent undue influence from outlying data. Minitab for Windows software was used for data analysis.

\section{Results}

Full clinical and demographic details for the 18 stable lung transplant recipients studied are summarized in table 1. All subjects had FEV1 measurements at, or near, their maximal post transplant (median 100\%, range $84-100 \%$ ), and were lung rejection grade A0 or A1 by standard grading techniques [2].

Immunosuppression at the time of investigation is shown in table 1 . The median cyclosporin blood level was $283 \mu \mathrm{g} \cdot \mathrm{L}^{-1}$ (range $134-820 \mathrm{mg} \cdot \mathrm{L}^{-1}$ ), median prednisolone dose $15 \mathrm{mg}$ (range $7.5-20 \mathrm{mg}$ ) daily and the median azathioprine dose $63 \mathrm{mg}$ (range 25-125 mg) daily. BAL culture or immunofluorescence revealed organisms in 11 cases, but all were considered both clinically and microbiologically to be commensals.

No complications ensued from the procedures. Specifically, there were no episodes of significant endobronchial haemorrhage or pneumothorax. The acquisition of EBBs added approximately $5 \mathrm{~min}$ to the standard bronchoscopic procedure.

\section{Comparison of EBB findings with $B A L$}

Suitable paired EBB and BAL specimens were available for analysis in 16 individuals (in two individuals BAL procedures were not performed due to oxygen desaturation during bronchoscopy). Table 2 summarizes the BAL and $\mathrm{EBB}$ data from these subjects.

There was no correlation between the total number of macrophages or lymphocytes in the two specimen types $(\mathrm{r}=-0.10, \mathrm{r}=-0.32$, respectively), nor in the number of $\mathrm{CD} 4+, \mathrm{CD} 8+$ or CD25+ cells $(\mathrm{r}=-0.28, \mathrm{r}=-0.41$ and $\mathrm{r}=$ -0.32 , respectively) when BAL and EBB were compared in this group of stable lung transplant subjects.

The BAL samples also gave qualitatively different cellular profiles when compared to EBB. In BAL, the alveolar macrophage was present in greater numbers than the lymphocyte (median $120 \times 10^{3}$ cells $\cdot \mathrm{mL}^{-1}$, interquartile range $89-168$ cells $\cdot \mathrm{mL}^{-1}$ versus $31 \times 10^{3}$ cells $\cdot \mathrm{mL}^{-1}$, interquartile range $15-79$ cells $\left.\cdot \mathrm{mL}^{-1}\right)$, and constituted the

Table 2. - Descriptive statistics and results of correlation analyses for 16 sets of paired endobronchial biopsy (EBB) and bronchoalveolar lavage (BAL) samples in clinically stable lung transplant recipients

\begin{tabular}{|c|c|c|c|c|c|c|c|}
\hline & $\begin{array}{l}\text { Return }^{\#} \\
\text { mL }\end{array}$ & $\begin{array}{c}\text { TCC } \\
\times 10^{3} \cdot \mathrm{mL}^{-1}\end{array}$ & $\mathrm{AM}$ & Lym & CD4+ & CD8+ & CD25+ \\
\hline BAL & $\begin{array}{c}87 \\
(40-112)\end{array}$ & $\begin{array}{c}150 \\
(100-1700)\end{array}$ & $\begin{array}{c}120 \\
(89-168)\end{array}$ & $\begin{array}{c}31 \\
(15-79)\end{array}$ & $\begin{array}{c}8 \\
(5-14)\end{array}$ & $\begin{array}{c}21 \\
(8-50)\end{array}$ & $\begin{array}{c}3 \\
(1-10)\end{array}$ \\
\hline EBB & - & - & $\begin{array}{c}100 \\
(81-172) \\
-010 \cdot\end{array}$ & $\begin{array}{c}75 \\
(45-112) \\
-032 \cdot\end{array}$ & $\begin{array}{c}34 \\
(15-44) \\
-0.28 \cdot\end{array}$ & $\begin{array}{c}56 \\
(32-77) \\
-041 \cdot\end{array}$ & $\begin{array}{c}1 \\
(0-2) \\
-032 .\end{array}$ \\
\hline
\end{tabular}

Data are presented as median, and interquartile range in parenthesis. BAL counts are expressed $\times 10^{3}$ cells $\cdot \mathrm{mL}^{-1}$. EBB counts are expressed as positive cells per $\mathrm{mm}$ basement membrane. TCC: total cell count; AM: alveolar macrophages; Lym: lymphocytes; Ns: nonsignificant. 
Table 3. - Comparison of BAL and EBB results between individuals with bronchiolar inflammation recognized at TBB and those without bronchiolar inflammation recognized at TBB

\begin{tabular}{lccccccc}
\hline & $\begin{array}{c}\text { Return\# } \\
\mathrm{mL}\end{array}$ & $\begin{array}{c}\text { TCC } \\
\times 10^{3} \cdot \mathrm{mL}^{-1}\end{array}$ & AM & Lym & CD4+ & CD8+ & CD25+ \\
\hline BAL & 100 & 260 & 145 & 54 & 9 & 45 & 6 \\
$(\mathrm{n}=4)$ & $(90-109)$ & $(150-430)$ & $(110-280)$ & $(19-296)$ & $(4-70)$ & $(11-216)$ & $(3-19)$ \\
$\begin{array}{l}\text { BAL (wo) } \\
(\mathrm{n}=8)\end{array}$ & 89 & 130 & 114 & 17 & 7 & 12 & 2 \\
EBB & $(46-110)$ & $(100-440)$ & $(70-330)$ & $(60-105)$ & $(2-35)$ & $(11-216)$ & $(1-10)$ \\
$(\mathrm{n}=5)$ & - & - & 96 & 58 & 34 & 49 & 1 \\
EBB (wo) & - & - & $(71-172)$ & $(35-106)$ & $(6-50)$ & $(28-77)$ & $(0-2)$ \\
$(\mathrm{n}=9)$ & & & 101 & 70 & 22 & 56 & 1 \\
\hline
\end{tabular}

Data are presented as median, and interquartile range in parenthesis. BAL counts are expressed $\times 10^{3}$ cells $\cdot \mathrm{mL}^{-1}$. EBB counts are expressed as positive cells per mm basement membrane. \#: volume return from a $180 \mathrm{~mL}$ BAL. BAL (wo) and EBB (wo): BAL and EBB results, respectively, from subjects without bronchiolar inflammation. TBB: transbronchial biopsy. For further definitions, see table 2 .

majority cell. In contrast, in EBB, the numbers of (tissue) macrophages were closer to the number of T-lymphocytes detected in EBB (median 100 cells $\cdot \mathrm{mm}^{-1}$ basement membrane, interquartile range $81-172$ cells $\cdot \mathrm{mm}^{-1}$ versus median 75 cells $\cdot \mathrm{mm}^{-1}$ basement membrane, interquartile range $45-112$ cells $\cdot \mathrm{mm}^{-1}$ ).

\section{Comparison of airway findings using $T B B, E B B$ and $B A L$}

Eighteen paired EBB and TBB specimens were available for comparison (table 1). Four of the TBB specimens did not yield any sample of airway. Nine of the specimens were categorized as being without bronchiolar inflammation, and the remaining five were categorized as having some bronchiolar inflammation present.

There were no significant differences in inflammatory indices measured in the EBB or BAL samples from subjects who were judged to have bronchiolar inflammation present in TBB compared to those without bronchiolar inflammation (table 3), although there was a trend for a higher BAL total and lymphocyte cell count in individuals who had inflammation present at TBB.

\section{Discussion}

The evaluation of methodology employed in bronchoscopic studies of lung transplantation may be of fundamental importance to the interpretation of results, and will influence whether emergent laboratory techniques become of clinical use. We chose to compare EBB, TBB and BAL results in this study in a clinically stable, posttransplant population with no clinical evidence of BOS. Acute infection was an exclusion criterion for our study population, and organisms, where cultured, were attributed to the presence of "commensals", in an overall stable clinical assessment. The absence of overt "lung" rejection was ascertained by the absence of clinical or investigative evidence, including chest radiograph, pulmonary function tests and TBB obtained at the time of the bronchoscopy. With lung function at, or near, the maximal post-transplant levels, the study group were all BOS category 0 . No patient included in the analysis subsequently changed category within 6 months of the study, confirming that clinically relevant BOS was not present.

The present study confirmed the practicability of performing and analysing EBBs in lung transplant recipi- ents, alongside the more traditionally studied TBB and BAL specimens. Of the samples tested, TBBs are currently considered the standard bronchoscopy-based sample for the monitoring of chronic rejection [8]. This is despite known disadvantages, including the need for large numbers of specimens [10], the possibility of complications following the procedure [13], and the frequent absence of airway tissue in the samples, as opposed to lung parenchyma.

This study confirmed that the yield of bronchiolar tissue using TBB specimens is variable. The present yield of around $78 \%$ was towards the higher levels of the range that has been documented previously [9]. Overall, of the 18 TBB specimens studied, 14 gave airway material and only five were categorized as indicating the presence of bronchial inflammation. By contrast, all the EBBs yielded adequate subepithelial airway material and inflammatory cells were detected in all specimens. We have recently published data indicating that the mononuclear cell population in these specimens is expanded, even in stable lung allografts [17], and that this may precede subsequent airway fibrosis present in BOS [18]. Hence, we can conclude from this study that EBB and TBB specimens are qualitatively very different and, from our cumulative experience, that EBB gives information that is of potential importance in the monitoring of lung allografts $[17,18]$. This simple finding may be especially important for studies into BOS, because the hallmark of this form of chronic rejection is functional change in the airway. The results imply that EBB may represent a relevant sampling adjunct to standard TBB in lung allograft surveillance. EBB gave good quantitative data, whereas TBB assessments performed according to current guidelines are semiquantitative and mean that only categorical results are available in the management of lung transplant recipients.

With respect to BAL, the other traditional sample taken during bronchoscopy of lung transplant recipients, studies so far have failed to define a clear role for it in the assessment of lung rejection, although it is useful in the monitoring of infection [8]. We found a trend for a higher BAL total and lymphocyte cell count in individuals who had inflammation present at TBB, although this was not significant in the small numbers available for this subanalysis. A possible explanation for this, in patients without infection, is that the $3 \times 60 \mathrm{~mL} \mathrm{BAL}$ protocol employed in this study, in fact, sampled relatively peripherally from the lung compartment. It should 
be noted that the available technology for more sophisticated assessment of BAL samples is evolving rapidly, particularly with regard to molecular biological approaches. Recent work has already indicated that cytokine gene expression might be a useful marker in studies of rejection [9], and that a serum to BAL supernatant IgG2/IgG1 ratio of $\geq 1$ had a specificity of $80 \%$, a sensitivity of $91 \%$, and a positive predictive value of $92 \%$ for rejection [19].

Of the cells present in BAL, alveolar macrophages constituted the majority, followed by T-lymphocytes, with the cytotoxic/suppressor subset $(\mathrm{CD} 8+)$ the predominant phenotype. The endobronchial biopsies that we sampled at the same time as BAL contained essentially equal numbers of macrophages and lymphocytes, but with CD8+ cells again representing the predominant T-cell phenotype. The available literature relating to the cellular pathology of chronic rejection in transplanted lungs [7], and the more comprehensive literature relating to other solid organ grafts [20], suggests that monitoring of these cell types may have a potential role in establishing prognostic markers for chronic rejection.

The different cellular profiles in the BAL and EBB samples of lung transplant recipients may be related to the fact that the cells in the BAL have migrated through the airway and lung interstitium into the airway lumen. Even within BAL, heterogeneity of single cell types has been shown, and phenotypically distinct populations of BAL macrophages have been described, with different cell functions [21]. It is, therefore, possible that the relative numerical differences between BAL and EBB are consistent with the existence of separate, compartmentalized populations of cells, and that the monitoring of both will give complimentary information relating to the lung allograft.

Overall, therefore, we conclude that the results of this study, together with our other recent studies [17, 18], indicate the potential usefulness of endobronchial biopsy in the assessment of lung allograft histopathology, since the method yields different information to bronchoalveolar lavage and transbronchial biopsy, and is potentially complimentary. Since endobronchial biopsies are safe, quick and can be routinely available, this strategy is practicable. The potential usefulness of endobronchial biopsy, taken in addition to bronchoalveolar lavage and transbronchial biopsy samples, needs to be investigated prospectively, in a longitudinal study of lung transplant recipients.

\section{References}

1. Cooper JD, Patterson GA, Trulock EP, and the Washington University Lung Transplant Group. Results of single and bilateral lung transplantation in 131 consecutive recipients. J Thorac Cardiovasc Surg 1994; 107: 460-471.

2. Yousem SA, Berry GJ, Cagle PT, Chamberlain D, Husain AN, Hruban R. Revision of the 1990 working formulation for the classification of pulmonary allograft rejection. J Heart Transplant 1996; 15: 1-15.

3. Yousem SA, Paradis IL, Dauber JA, et al. Large airway inflammation in heart-lung transplant recipients its significance and prognostic implications. Transplantation 1990; 49: 654-656.
4. Novick RJ, Ahmad D, Menkis AH, Reid KR, Pflugfelder PW, McKenzie FN. The importance of acquired diffuse bronchomalacia in heart-lung transplant recipients with obliterative bronchiolitis. J Thorac Cardiovasc Surg 1991; 101: 643-648.

5. Kramer MR, Stoehr C, Whang JL, et al. The diagnosis of obliterative bronchiolitis after heart-lung and lung transplantation: low yield of transbronchial biopsy. $J$ Heart Lung Transplant 1993; 12: 675-681.

6. Griffith BP. Detection of rejection in the transplanted lungs and immunology. In: Wallwork JW, ed. Heart and Heart-Lung Transplantation. Philadelphia, W.B. Saunders Co., 1989; pp. 507-521.

7. Ohori PN, Yousem SA. Pathology of lung transplantation. In: Solez K, Racusen LC, Billingham ME, eds. Solid Organ Transplant Rejection; Mechanisms, Pathology and Diagnosis. New York, Marcel Dekker, 1996; pp. 161-185.

8. Valentine VG, Robbins RC, Theodore J. Clinical Diagnosis in Allograft Rejection. In: Solez K, Racusen LC, Billingham ME, eds. Solid Organ Transplant Rejection; Mechanisms, Pathology and Diagnosis. New York, Marcel Dekker, 1996; pp. 327-366.

9. Trulock EP. State of the art: lung transplantation. Am J Respir Crit Care Med 1997; 155: 789-818.

10. Scott JP, Fradet G, Smyth RL, et al. Prospective study of transbronchial biopsies in the management of heartlung and single lung transplant patients. J Heart Lung Transplant 1991; 10: 626-636.

11. Shennib H, Nguyen D. Bronchoalveolar lavage in lung transplantation. Ann Thorac Surg 1991; 51: 335-340.

12. Trulock EP, Ettinger NA, Brunt EM, Pasque MK, Kaiser LR, Cooper JD. The role of transbronchial biopsy in the treatment of lung transplant recipients: an analysis of 200 consecutive procedures. Chest 1992; 102: 1049-1052.

13. Tazelaar HD, Nilsson FN, Rinaldi M, Mutagh P, McDougall JC, McGregor CGA. The sensitivity of transbronchial biopsy for the diagnosis of acute lung rejection. J Thorac Cardiovasc Surg 1993; 105: 674-678.

14. Yousem SA, Paradis I, Griffith BP. Can transbronchial biopsy aid in the diagnosis of bronchiolitis obliterans in lung transplant recipients? Transplantation 1994; 57: 151-153.

15. Farrel D, Healy M, Dark JD, Corris PA. Lymphocyte infiltrates in bronchial biopsies from large airways in patients after lung transplantation (Abstract). Eur Respir $J$ 1995; 8: 450S.

16. Fournier M, Igual J, Groussard O, et al. Mucosal Tlymphocytes in central airways of lung transplant recipients. Am J Respir Crit Care Med 1995; 151: 1974-1980.

17. Snell GL, Ward C, Wilson JW, Orsida B, Williams TJ, Walters EH. Immunopathological changes in the airways of stable lung transplant recipients. Thorax 1997; 52: 322-328.

18. Zheng L, Ward C, Snell GI, et al. Scar collagen deposition in the airways of allografts of lung transplant recipients. Am J Respir Crit Care Med 1997; 155: 2072-2077.

19. Wilkes D, Heidler K, Niemeier M, et al. Increased bronchoalveolar lavage $\mathrm{IgG} 2 / \mathrm{IgG} 1$ ratio is a marker for human lung allograft rejection. J Investig Med 1994; 42: 652659.

20. Solid Organ Transplant Rejection; Mechanisms, Pathology and Diagnosis. Solez K, Racusen LC, Billingham ME, eds. New York, Marcel Dekker, 1996; pp. 1-633.

21. Matthes ML, Steinmuller C, Franke-Ullman G. Pulmonary macrophages. Eur Respir J 1994; 7: 1678-1689. 